\title{
Thermal aging resistance of natural rubber compounded with conjugated Schiff base
}

DOI: dx.doi.org/10.14314/polimery.2022.1.3

\author{
Jianfa Wang ${ }^{1)}$ (ORCID ID: 0000-0002-1242-3794), Zheng Gu ${ }^{1), 2), ~ *) ~(0000-0001-9521-2863), ~ S u s u ~ Z h a n g 1) ~(0000-0003-3620-0816), ~}$ \\ Ning Wang ${ }^{1)}(0000-0003-0693-8318)$, Jinyong Sui ${ }^{1)}$ (0000-0002-4232-3540), Xiaoyi Zhang') ${ }^{10}$ (0000-0003-4047-5046), \\ Peiyao Li ${ }^{3)}(0000-0002-4713-1599)$, Wenjin Liu $^{3)}$ (0000-0001-5563-1801), Yifan Hü ${ }^{3)}(0000-0002-3608-5419)$
}

\begin{abstract}
Schiff's base iron salt can be used as a new and effective antioxidant for rubber compounds. The tensile strength after $96 \mathrm{~h}$ of aging was approx. 36\% and 12\% higher, respectively, than in the case of the antioxidants 4010NA and BHT used. Natural rubber vulcanizate (NR) containing the iron salt of Schiff's base showed excellent rheological and mechanical properties, as well as very good thermal stability. These properties were far superior to that of other commercially available antioxidant rubber blends.
\end{abstract}

Keywords: Schiff base iron salt, natural rubber, thermal aging resistance.

\section{Badanie odporności na starzenie termiczne kauczuku naturalnego zawierającego sprzężoną zasadę Schiffa}

Streszczenie: Sól żelazowa zasady Schiffa może być stosowana jako nowy i skuteczny przeciwutleniacz do mieszanek gumowych. Wytrzymałość na rozciąganie po 96 h starzenia była odpowiednio o ok. 36\% i 12\% większa niż w przypadku stosowanych przeciwutleniaczy 4010NA i BHT. Wulkanizat kauczuku naturalnego (NR) zawierający sól żelazową zasady Schiffa wykazywał doskonałe właściwości reologiczne, mechaniczne, a także bardzo dobrą stabilność termiczną. Właściwości te były o wiele lepsze niż innych, dostępnych na rynku, przeciwutleniaczy mieszanek gumowych.

Słowa kluczowe: sól żelazowa zasady Schiffa, kauczuk naturalny, odporność na starzenie.

Natural rubber (NR) is easily affected by free radicals induced by heat, light, and oxygen/ozone, resulting in deterioration of mechanical properties during processing or application. NR is a natural high molecular polymer with molecular formula $\left(\mathrm{C}_{5} \mathrm{H}_{8}\right)_{\mathrm{n}}$ (Fig. 1), which main component is polyisoprene (more than 90\%) and the content of non-rubber substances such as carbohydrates, fatty acids, protein substances, and ash is low. Like in case of the other free radical reactions, thermal oxidative degradation of NR is carried out through the free radical chain mechanism, in which alkyl radicals $(\mathrm{R})$ and oxygen free radicals ( $\mathrm{ROO}^{-}, \mathrm{RO}^{-}$) cause chain initiation and growth [1]. It is necessary to reduce or inhibit degradation by introducing antioxidants during processing, which role is to react with oxygen center of free radicals or alkyl free radicals to destroy the propagation of positive free radical

\footnotetext{
1) College of Chemistry and Chemical Engineering, Qingdao University, China 266071.

2) Weihai Innovation Institute, Qingdao University, China 264200.

3) College of Materials Science and Engineering, Qingdao University, China 266071.

*) Author for correspondence: guzheng596@163.com
}

chains [2]. Hindered phenol antioxidants and hindered amine antioxidants (HPAOs and HAAOs) are the two main categories of traditional antioxidants [3-5].

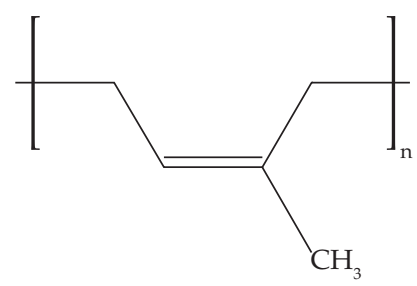

Fig. 1. Chemical formula of natural rubber

Many scientists have made effective examinations on rubber antioxidants. Cataldo [6] reviewed researches on ozone-resistant protection technology for rubber compounds. The topics covered static ozone protection using paraffin wax and dynamic ozone protection using disubstituted $p$-phenylenediamine. The review focused on the one of the most commonly substituted standard rubber compounds (including a non-staining type) of $p$-phenylenediamine and the ozone resistance and flexible fatigue life of rubber under dynamic conditions. Cerna et al. [7] used non-isothermal differential scanning calorimetry 
(DSC) to study iminostilbene, phenothiazine, diphenylamine, trisubstituted diphenylamine and $N-(1,3-$ -dimethylbutyl)-N'-phenylbenzene-1,4-diamine (6PPD) in the antioxidative process of styrene butadiene rubber (SBR) thermal oxidation reaction. Among these monomer compounds, SBR had the most stable antioxidant properties to iminostilbene. Additionally, a mixture of 6PPD and 4-phenylaminophenol had the best stability. The S-factor value was used to characterize the synergistic effect of antioxidants in binary mixtures. The results proved that only the mixture of 6PPD and 4-phenylaminophenol had a synergistic effect at $130^{\circ} \mathrm{C}$. George et al. [8] studied the photochemical degradation of natural rubber (NR) in a solution with ethylenediamine to obtain amino-terminated liquid natural rubber (ATNR). ATNR reacted with glyoxal to form Schiff base, which can improve the anti-aging performance of natural rubber.

Development of more efficient NR antioxidants is still the focus of researches [9]. Styrylphenol, 2,2-methylenebis(6-tert-butyl-4-methylphenol), and 2,6-di-tert-butyl-4-methylphenol have been widely used in NR. In many cases, HPAOs are produced in the reaction of active hydrogen $(\mathrm{ArOH})$ with phenol in which $\mathrm{ROO}^{-}$generate aryloxy radicals (ArO) and peroxygen compounds $(\mathrm{ROOH})$, and continuously ROO- are captured to generate non-radical products ( $\mathrm{ROO}^{-}, \mathrm{O}, \mathrm{Ar}$ ), that carry out chain breaking free radical reaction. Su Ch. et al. [10] found that the antioxidant efficiency of $p$-phenylenediamine derivatives increased with the increase of the substituent inducing effect. In fact, Schiff base antioxidants showed a great potential in promoting the anti-aging of NR. Such antioxidants are generally formed by the condensation of amines and active carbonyl groups. However, further investigations and studies on Schiff base antioxidants are lacking.
In this study, two new Schiff base iron salt antioxidants were synthesized. The effects of Schiff base antioxidants on the rheological and mechanical properties, as well as thermal oxidation stability of NR vulcanizates were examined.

\section{EXPERIMENTAL PART}

\section{Materials and equipment}

The large quantity of chemicals were used in our experiments. The used materials and equipment are listed in Table 1 and Table 2.

\section{Methods}

\section{Synthesis of $p$-phenylenedialdehyde condensed $p$-phenylenediamine long-chain conjugated poly(Schiff base) $\mathrm{L} 1$ and its iron salt $\mathrm{C} 1$}

0.04 mol of $p$-phenylenediamine was fully dissolved in $80 \mathrm{ml}$ of absolute ethanol and transferred into a $250 \mathrm{ml}$ three-necked flask. A small amount of glacial acetic acid was used as a catalyst. The temperature was raised to $75^{\circ} \mathrm{C}$, the mixture was stirred until it was completely dissolved. Then $0.04 \mathrm{~mol}$ of terephthalaldehyde was dissolved in $60 \mathrm{ml}$ of absolute ethanol. The mixture was then poured into a constant pressure dropping funnel, used 1 drop/sec dropping acceleration, and titrated slowly into a $250 \mathrm{ml}$ three-necked flask, under the protection of $\mathrm{N}_{2}$. After that the mixture was refluxed and heated for 8 hours. The color of the solution changed from yellow to orange-red. After the heating was over, a sample was put into the ultrasonic shaker and shook for 15 minutes. The

T a b l e 1. Materials

\begin{tabular}{|c|c|c|}
\hline Experimental raw materials & Manufacturer & Other information \\
\hline Schiff base & Self-made & \\
\hline 2,6-di-tert-butyl-4-methylphenol (BHT) & Shanghai Feiige Chemical Co., Ltd & $\begin{array}{l}\text { Typical commodity anti- } \\
\text {-aging prevention agent } \\
\text { Reduces rubber aging degree }\end{array}$ \\
\hline $\begin{array}{l}N \text {-isopropyl-N'-phenyl-1,4- } \\
\text {-phenylenediamine (4010NA) }\end{array}$ & $\begin{array}{l}\text { Guangzhou Rubber Industry } \\
\text { Research Institute Co., Ltd }\end{array}$ & $\begin{array}{l}\text { Common rubber anti-aging agent } \\
\text { Reduces rubber aging degree }\end{array}$ \\
\hline Natural rubber (NR) & Vietnam & \\
\hline $\begin{array}{l}N \text {-cyclohexyl-2-benzothiazole } \\
\text { sulfenamide }(\mathrm{CZ})\end{array}$ & Guangzhou ben Rubber Materials Co., Ltd & $\begin{array}{l}\text { High-speed vulcanizing agent } \\
\text { to accelerate vulcanization }\end{array}$ \\
\hline Dibenzothiazyl disulfide (DM) & Guangzhou ben Rubber Materials Co., Ltd & $\begin{array}{l}\text { Low-speed vulcanizing agent } \\
\text { to accelerate vulcanization }\end{array}$ \\
\hline Zinc oxide (analytical grade) & China Xilong Chemical Co., Ltd & $\begin{array}{c}\text { Activator } \\
\text { Rubber modifier, vulcanizing oxidizer }\end{array}$ \\
\hline Sublimed sulfur & China Xilong Chemical Co., Ltd & Vulcanization to crosslink the rubber \\
\hline Stearic acid (SA) & $\begin{array}{l}\text { China Weener Functional } \\
\text { Materials Corporation }\end{array}$ & $\begin{array}{l}\text { Vulcanizing activator, can be used } \\
\text { as plasticizer and softener }\end{array}$ \\
\hline Anhydrous ethanol (analytical grade) & $\begin{array}{c}\text { China Guangzhou Chemical } \\
\text { Reagent Co., Ltd }\end{array}$ & \\
\hline
\end{tabular}


T a b l e 2. Experimental and test equipment

\begin{tabular}{c|c}
\hline Experimental equipment & Manufacturer \\
\hline S(X)K-160A double-roller glue opener & Wuxi Wantailong Company \\
Type xl13-dx flat plate vulcanizer & Shanghai Yayun Equipment Company \\
Vulcanization on a type XLB/350.350.2 plate vulcanizer & Shanghai Qicai Hydraulic Machinery Co., Ltd \\
No rotor-type sulcanator & Shanghai Wenzhou Weidu Electronics Co., Ltd \\
Electronic tension test machine & Shanghai Dejie Instrument and Equipment Co., Ltd \\
Shore Type A hardness meter & Shanghai Wenzhou Weidu Electronics Co., Ltd \\
Type TGA/STDA851 thermogravimetric analyzer & Mettler/Toledo, Inc \\
Lichen blast drying oven & Shanghai Lichen Technology Company \\
\hline
\end{tabular}

product solution was washed and filtrated under vacuum conditions 2-3 times with absolute ethanol and distilled water. The filter cake was put into a vacuum dryer and dried in $50^{\circ} \mathrm{C}$ for 12 hours. The final product was a golden yellow powder. The yield was $72 \%$. Melting point of the sample was $320^{\circ} \mathrm{C}$. The synthesis route is shown in Fig. 2.

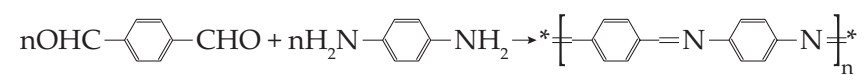

Fig. 2. Synthesis of $p$-phenylenediamine poly(Schiff base) L1 condensed by $p$-phenylenedialdehyde

0.04 mol of $p$-phenylenediamine was fully dissolved in $80 \mathrm{ml}$ of absolute ethanol and transferred into a $250 \mathrm{ml}$ three-necked flask. A small amount of ice acetic acid was added as a catalyst. The mixture was heated up to $75^{\circ} \mathrm{C}$ and stirred till the complete dissolving. $0.04 \mathrm{~mol}$ of terephthalaldehyde was dissolved with $60 \mathrm{ml}$ of absolute ethanol. The mixture was poured into a constant pressure dropping funnel, used $1 \mathrm{drop} / \mathrm{sec}$ dropping acceleration, and titrated with a constant pressure. Afterwards the mixture was slowly and dropwise transferred into a $250 \mathrm{ml}$ three-necked flask. The prepared terephthalaldehyde condensed p-phenylenediamine poly(Schiff base) mixed solution reactant was transferred into the three-necked flask. $0.04 \mathrm{~mol}$ $(6.46 \mathrm{~g})$ of anhydrous $\mathrm{FeCl}_{3}$ was dissolved in $60 \mathrm{ml}$ of anhydrous ethanol and slowly titrated at a constant pressure into a three-necked flask containing the poly(Schiff base) mixed solution. The color of the sample solution gradually changed from orange-red to dark-brown. After dripping was completed, temperature was raised to $75^{\circ} \mathrm{C}$. The reaction was refluxed under the protection of $\mathrm{N}_{2}$ for 8 hours, filtrated, washed and dried. The synthesis is shown in Fig. 3.

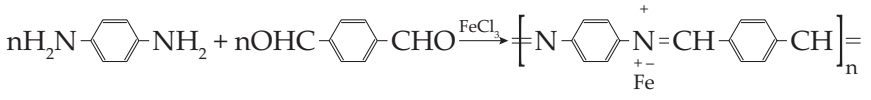

Fig. 3. Synthesis of $p$-phenylenedialdehyde condensed $p$-phenylenediamine poly(Schiff base) iron salt $\mathrm{C} 1$

Synthesis of glyoxal condensed $p$-phenylenediamine long-chain conjugated poly(Schiff base) L2 and its iron salt C2

0.04 mol of $p$-phenylenediamine was fully dissolved in $80 \mathrm{ml}$ of absolute ethanol, and then the mixture was trans- ferred into a $250 \mathrm{ml}$ three-necked flask. The temperature was raised to $75^{\circ} \mathrm{C}$ and the mixture was stirred until it was completely dissolved. $0.04 \mathrm{~mol}$ of glyoxal, dissolved in $40 \mathrm{ml}$ of absolute ethanol, was poured into a constant pressure dropping funnel, used 1 drop/sec dropping acceleration, titrated slowly into a $250 \mathrm{ml}$ three-necked flask, condensed under the protection of $\mathrm{N}_{2}$, refluxed and heated for 8 hours. The color of the solution changed from yellow to reddish brown. When the temperature was cooled down to a room temperature, the product was washed and dried. Its form was an orange-red powder. The yield was $82 \%$. The synthesis is depicted in Fig. 4.

$$
\left.\mathrm{nH}_{2} \mathrm{~N}-2 \mathrm{NH}_{2}+\mathrm{nOHC}-\mathrm{CHO} \longrightarrow \mathrm{f}-\longrightarrow \mathrm{N}=\mathrm{CH}-\mathrm{CH}\right]_{\mathrm{n}}
$$

Fig. 4. Synthesis of glyoxal condensed $p$-phenylenediamine poly(Schiff base) L2

$0.04 \mathrm{~mol}$ of $p$-phenylenediamine, dissolved in $80 \mathrm{ml}$ of absolute ethanol, was transferred into a $250 \mathrm{ml}$ three-necked flask. The temperature was raised to $75^{\circ} \mathrm{C}$, and the mixture was stirred until it was completely dissolved. $0.04 \mathrm{~mol}$ of glyoxal was dissolved in $40 \mathrm{ml}$ of absolute ethanol. The mixture was poured into the constant pressure dropping funnel, used 1 drop/sec dropping acceleration, and titrated slowly and dropwise into a $250 \mathrm{ml}$ three-necked flask. $0.04 \mathrm{~mol}$ of anhydrous $\mathrm{FeCl}_{3}$ was fully dissolved in $60 \mathrm{ml}$ of anhydrous ethanol. After the reactants fully reacted, the solution was titrated slowly and under constant pressure to a three-necked flask. The color changed gradually from orange-red to black. After the dropwise addition was completed, the temperature was adjusted to $75^{\circ} \mathrm{C}$, and the solution was refluxed for $8 \mathrm{~h}$ by condensation. After the temperature was cooled down to a room temperature, the product was filtered under vacuum conditions. The filter cake was washed two to three times with absolute ethanol and dried for 4 hours. The final product, glyoxal condensed $p$-phenylenediamine conjugated poly(Schiff base) iron salt, was obtained with the yield of $70 \%$. The schematic of the synthesis is shown in Fig. 5.

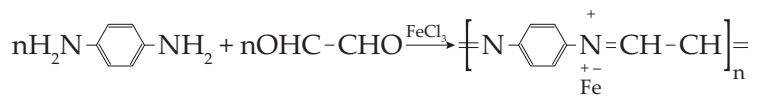

Fig. 5. Synthesis of glyoxal condensed $p$-phenylenediamine poly(Schiff base) iron salt C2 


\section{Processing and synthesis of natural rubber}

The vulcanizate contained: $100 \mathrm{~g}$ of natural rubber (NR), $1.875 \mathrm{~g}$ of accelerator CZ, $0.625 \mathrm{~g}$ of accelerator DM, $1 \mathrm{~g}$ of stearic acid, $5 \mathrm{~g}$ of zinc oxide, $1.875 \mathrm{~g}$ of sulfur, and $2.0 \mathrm{~g}$ of Schiff base antioxidant. All abbreviations are explained in Table 1.

The vulcanized rubber was plasticized in $S(X) K-160 A$ double-roller glue opener (Wuxi Wantailong), and then vulcanized using xl13-dx flat vulcanizing machine (Shanghai Yayue). The NR vulcanizates prepared by adding C1, C2, BHT, and 4010NA were denoted as NR-1, NR-2, NR-3, and NR-4, respectively; the NR vulcanizate without any anti-aging agent was denoted as NR-0. In order to examine the suitability of Schiff base iron salts $\mathrm{C} 1$ and $\mathrm{C} 2$ antioxidants in industrial formulations, carbon black, a rubber reinforcing agent used widely in the industry because of its excellent properties, was added to a rubber in an amount of $50 \mathrm{~g}$. The samples of NR vulcanizates with carbon black and C1, C2, BHT, or 4010NA antioxidants were denoted CNR-1, CNR-2, CNR-3, and CNR-4, respectively, and the NR vulcanizate without any antioxidants was CNR-0. The vulcanization was performed using XLB/350.350.2 flat vulcanizing machine (Shanghai Qicai Hydraulic Machinery Co., Ltd). After mixing, the sheet was passed thinly. After the film was discharged, it was put into the mold and vulcanized using xl13-dx flat vulcanizer (Shanghai Yayue). The vulcanization time was $T_{c 90}$ time plus 2 minutes. After the film was discharged for more than 8 hours, it was cut out a thickness of $2 \mathrm{~mm}$ using a manual die cutting machine. $4 \mathrm{~mm}$ test specimens were placed into a Lichen blast drying oven with a gradient of $24 \mathrm{~h}$ and an aging temperature of $60^{\circ} \mathrm{C}$ to ensure sufficient oxygen content for thermal aging experiments. A batch of specimens was taken out every $24 \mathrm{~h}$ for mechanical testing.

\section{Analytical and testing methods}

\section{Vulcanization characteristics test}

According to GB/T16584/1996, the vulcanization characteristics of rubber compound was determined using non-rotor vulcanization instrument (MDR2000 Shanghai Dejie instrument and Equipment Co., Ltd.). The oscillation frequency was $1.7 \mathrm{~Hz}$ (100 cycles/min), and the amplitude was $0 \pm 0.5$.

\section{Mechanical properties test}

According to GB/T528/1998 and GB530/1981, the tensile properties and tear strength of the samples were tested using electronic tensile testing machine (DXLL/50000 Shanghai Dejie Instrument Equipment Co., Ltd.) with the crosshead speed of $500 \mathrm{~mm} / \mathrm{min}$.

\section{Hardness test}

According to GB/T2411/2008, the hardness of vulcanizates was measured with Shore A hardness tester.

\section{TG characterization}

TGA/STDA851 thermogravimetric analyzer (Mettler/ Toledo) was used to determine the TG curves of the sample. Heating rate was $10^{\circ} \mathrm{C} / \mathrm{min}$, temperature range was $25-700^{\circ} \mathrm{C}$, the sample was protected by $\mathrm{N}_{2}$. Anhydrous ethanol (analytical grade) was provided by Guangzhou Chemical Reagent Co., Ltd.

\section{RESULTS AND DISCUSSION}

\section{Rheological properties of NR sulfide gel with different aging agents}

The rheological properties of NR vulcanizates after adding various antioxidants are listed in Table 3. Comparing to NR-0, NR-3, and NR-4, the minimum $\left(M_{L}\right)$ and maximum torque $\left(M_{H}\right)$ of NR-1 and NR-2 were lower. After adding Schiff base iron salts $\mathrm{C} 1$ and $\mathrm{C} 2$, the $M_{L}$ decreased, indicating that the fluidity was improved. Reduction of NR crosslinking density before aging was related to $M_{H}$ reduction. The addition of Schiff base iron salts $\mathrm{C} 1$ and $\mathrm{C} 2$ resulted in longer vulcanization time $\left(T_{c 90}\right)$ and scorch time $\left(T_{s 1}\right.$ and $\left.T_{s 2}\right)$, improving the safety of NR sample manufacturing. Comparing with industrial

T a b l e 3. Rheological properties of NR vulcanizates with various antioxidants

\begin{tabular}{|c|c|c|c|c|c|}
\hline Sample & $\begin{array}{c}M_{L} \\
\mathrm{dNm}\end{array}$ & $\begin{array}{c}M_{H} \\
\mathrm{dNm}\end{array}$ & $\begin{array}{c}T_{c 90} \\
\mathrm{~min}\end{array}$ & $\begin{array}{c}T_{s 1} \\
\mathrm{~min}\end{array}$ & $\begin{array}{c}T_{s 2} \\
\mathrm{~min}\end{array}$ \\
\hline NR-0 & 0.43 & 4.15 & $4: 57$ & $2: 33$ & 3:04 \\
\hline NR-1 & 0.40 & 3.87 & $5: 22$ & 3:04 & $3: 40$ \\
\hline NR-2 & 0.40 & 4.03 & $4: 59$ & $2: 50$ & $3: 24$ \\
\hline NR-3 & 0.43 & 4.09 & $4: 50$ & $2: 38$ & 3:11 \\
\hline NR-4 & 0.42 & 4.30 & $4: 41$ & $2: 33$ & 3:01 \\
\hline CNR-0 & 1.49 & 12.23 & $5: 26$ & $1: 27$ & $1: 51$ \\
\hline CNR-1 & 1.52 & 11.43 & $5: 21$ & $1: 31$ & $1: 55$ \\
\hline CNR-2 & 1.68 & 12.11 & $4: 40$ & 1:15 & $1: 36$ \\
\hline CNR-3 & 1.32 & 11.84 & $5: 21$ & $1: 27$ & $1: 53$ \\
\hline CNR-4 & 1.58 & 12.38 & 5:07 & $1: 23$ & $1: 48$ \\
\hline
\end{tabular}




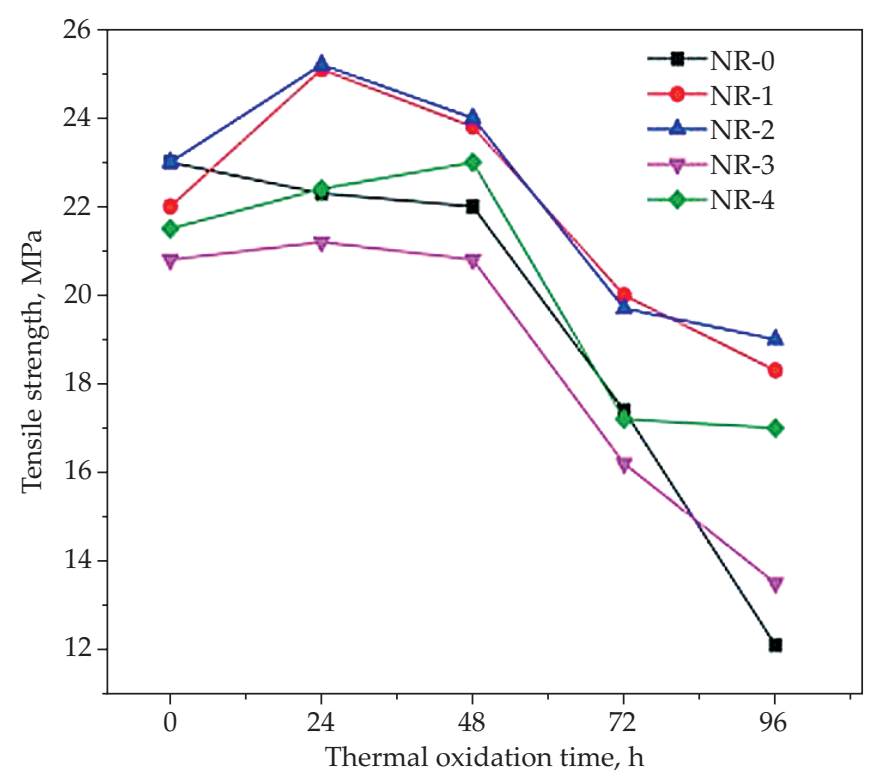

Fig. 6. Tensile strength of NR vulcanizates with different antioxidants as a function of thermal oxidation time

BHT and 4010NA, the newly synthesized Schiff base iron salt had better performance in promoting the rheological properties of NR samples. In case of CNR samples, an increase of $M_{L}$ and a decrease of $T_{c 90}$ indicated a decrease in fluidity and a shortened vulcanization time, respectively. Comparing to $\mathrm{C} 2$, the introduction of $\mathrm{C} 1$ improved the operational safety of CNR samples. For different formulations of NR vulcanizates (NR and CNR), Schiff base iron salts $\mathrm{C} 1$ and $\mathrm{C} 2$ were advantageous in improving rheological properties.

\section{Mechanical properties of NR vulcanizates with different antioxidants}

It can be seen in Fig. 6, that as the thermal oxidation time increased, the tensile strength firstly increased and then gradually decreased. The tensile performance of NR-2 decreased less than NR vulcanizates containing other antioxidants. The best oxidation performance was observed for NR-1 and NR-2.

As the thermal oxidation time increased, the elongation at break gradually decreased (Fig. 7). As can be seen in Fig. 7, the elongation at break of the NR vulcanizates decreased. The reduction of elongation at break of vulcanizates NR-3 and NR-4 with the increase of thermal oxidation time was smaller than that of NR vulcanizates NR-2 and NR-1. The difference between NR vulcanizates was very small.

The constant elongation stress is an important indicator to characterize the rigidity (resistance to the deformation force) of elastomer materials such as rubber, that is, to characterize the force of resistance to deformation required for a certain deformation of the tested material. The constant elongation stress corresponds to the tensile deformation performance of the material. It is the ability of material to resist external forces under a cer-

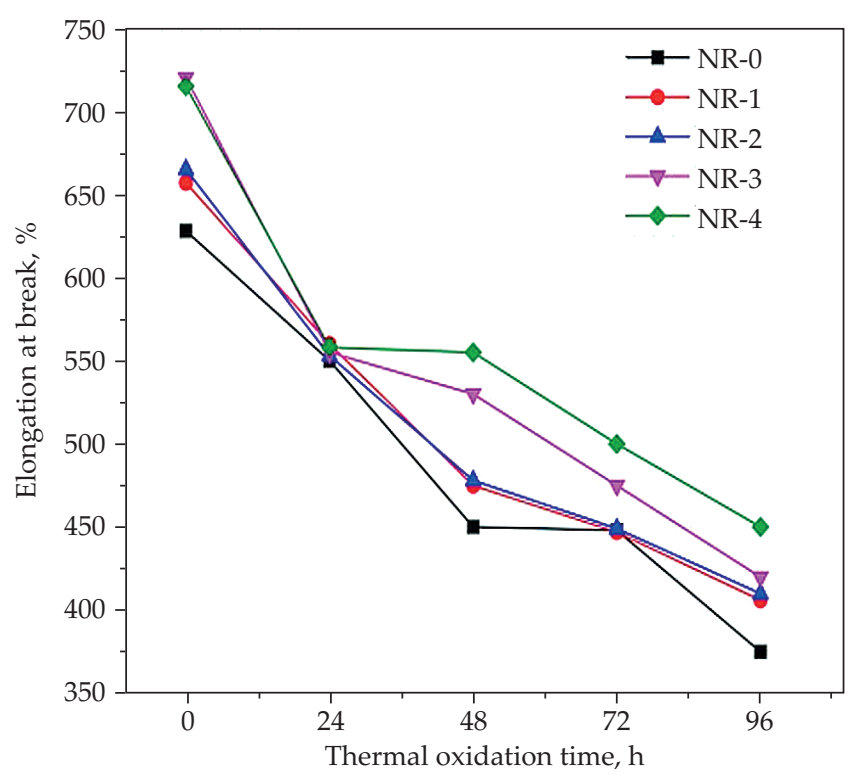

Fig. 7. Elongation at break of NR vulcanizates with different antioxidants as a function of thermal oxidation time

tain deformation and mainly shows the level of restriction of the filler on the rubber macromolecular chain. The greater the constant elongation stress of the composite material, the stronger the restriction of the filler on the rubber macromolecular chain. According to Figure 8, as the thermal oxidation time increased, the $100 \%$ constant elongation stress gradually increased. The increase in elongation at break of NR-3 and NR-4 vulcanizates was less than that of NR vulcanizates NR-2 and NR-1, indicating that NR-1 and NR-2 were better than those made with commercially available antioxidants, and had strong ability to resist external force under certain deformation and excellent mechanical properties.

Hardness is an important indicator of the rigidity of rubber materials. It is the ability of rubber to locally resist pressing of hard objects on the surface [11]. It can be seen in Figure 9 that the hardness of NR vulcanizate without any anti-aging agent increased slowly with the increase of thermal oxidation time, and its performance was poor among all vulcanizates. Vulcanizates NR-3 and NR-4 had strong hardness and superior performance.

\section{Mechanical properties of CNR vulcanizates reinforced by carbon black with different antioxidants and their comparison to NR vulcanizates}

Mechanical properties of NR and CNR samples with addition of various antioxidants and under thermal oxidative aging are shown in Figs. 6-9 and Figs. 10-13 respectively. The tensile strength of NR-0 and CNR-0 samples gradually decreased during $96 \mathrm{~h}$ of aging process. The tensile strength of NR samples with antioxidants $\mathrm{C} 1$ and $\mathrm{C} 2$ added but without carbon black reinforcement firstly increased within $24 \mathrm{~h}$ and $48 \mathrm{~h}$ of aging, and after that gradually decreased with the aging time (Fig. 6). The increase of tensile strength within 24 and $48 \mathrm{~h}$ 


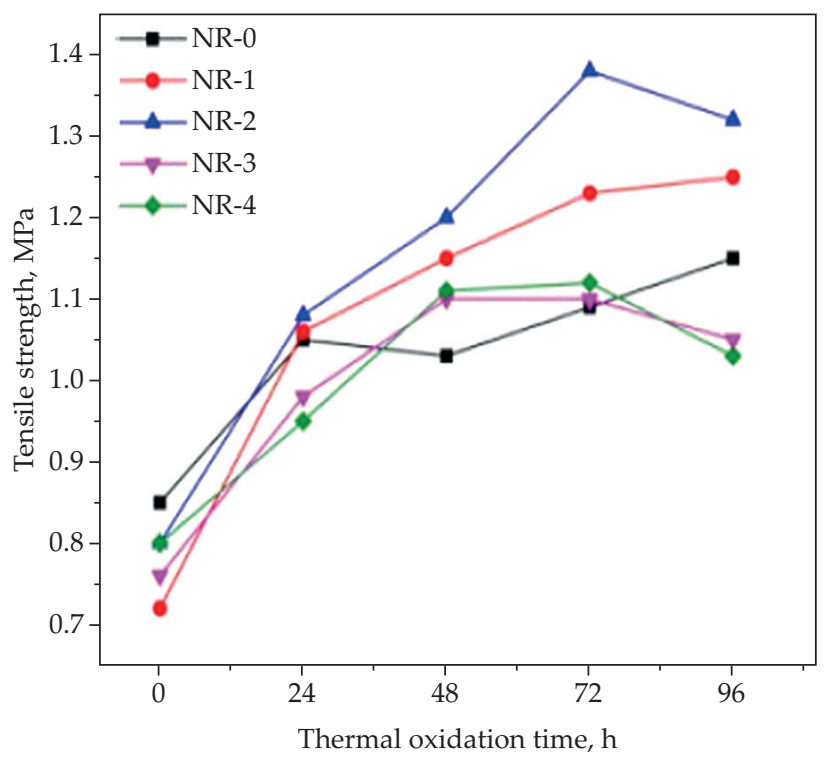

Fig. 8 . Tensile strength at $100 \%$ elongation of NR vulcanizates with different antioxidants as a function of thermal oxidation time

of aging might be related to the antioxidant promotion of the internal rubber crosslinking density during the aging process. The internal crosslinking of NR molecules was changing continuously with the aging time. Previous studies have shown that the tensile strength of NR with anti-aging agent reached its maximum after 24 hours of aging. In case of CNR samples the tensile strength gradually decreased within the whole $96 \mathrm{~h}$ of aging process (Fig. 10). The hard carbon black in CNR was blocking the internal crosslinking of rubber and weakened its impact on tensile strength. The elongation at break of CNR samples decreased with the increase of oxidative aging time (Fig. 11) similarly to NR samples without carbon black added (Fig. 7). The 100\% elongation and hardness of vulcanized NR samples without carbon black (Figs. 8 and 9) and CNR samples with its addition (Figs. 12 and 13) increased with aging time. After 96 hours of aging, samples with antioxidants C1 and C2 added (NR-1, NR-2, CNR-1, CNR-2) showed higher elongation stress than vulcanizates without any antioxidants (NR-0, CNR-0). The high Shore $\mathrm{A}$ hardness revealed the anti-aging effects of $\mathrm{C} 1$ and C2. After $96 \mathrm{~h}$ of oxidative aging, the tensile strength, $100 \%$ elongation stress, and Shore hardness of vulcanizates NR-3, NR-4, CNR-3, CNR-4 were lower than that of NR-1, NR-2, CNR-1, CNR-2.

\section{TG thermal stability of NR vulcanizates with different antioxidants}

As can be seen in Fig. 14, the weight loss rate of NR-1 and NR-2 under different degradation temperature conditions was higher than that of NR-3. The results showed that, comparing with BHT addition, $\mathrm{C} 1$ and $\mathrm{C} 2$ significantly delayed the degradation of NR vulcanizates during thermal oxidation. In addition, Schiff base and

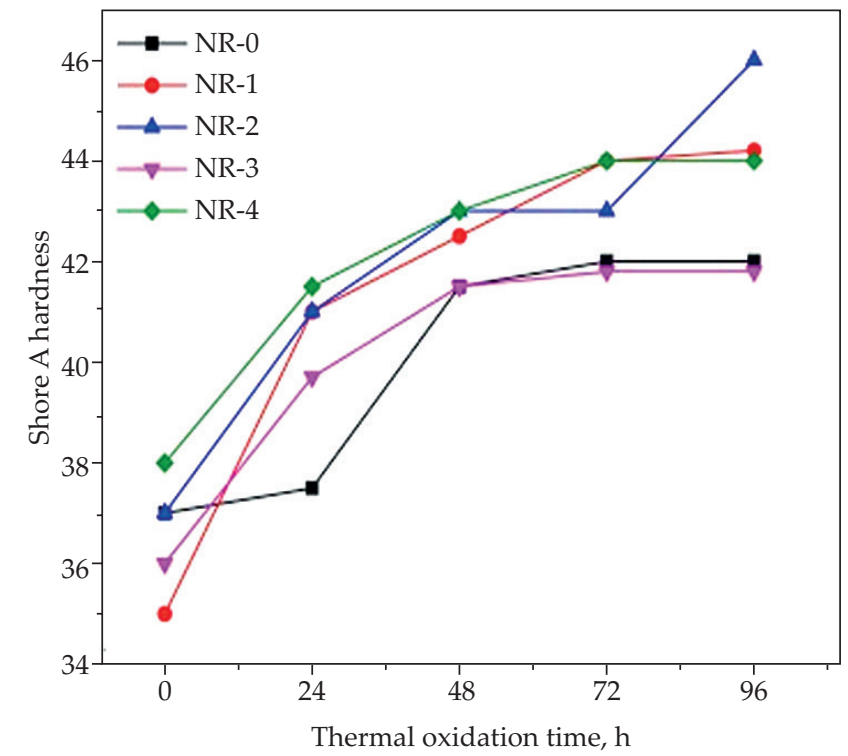

Fig. 9. Shore A hardness of NR vulcanizates with different antioxidants as a function of thermal oxidation time

4010NA antioxidants also showed their own advantages. The resistance to thermal oxidative aging of $\mathrm{C} 1$ and $\mathrm{C} 2$ may be related to the steric hindrance of the benzene ring. Under this action, these two compounds can provide more active hydrogen, which can capture the compounds generated during thermal oxidative aging. The resistance to thermal oxidative aging of $\mathrm{C} 1$ and $\mathrm{C} 2$ may occur due to Ar-NH-Ar structure and $\mathrm{C}=\mathrm{N}$ double bonds, as well as the interaction between them, which promotes the release of active hydrogen and captures more free radicals. In addition, the lone pair of electrons on the nitrogen atom is also beneficial to delay or terminate the free radical reaction.

The thermal oxidation stability and kinetics of NR samples were further studied and results are shown in Table 4 . The maximum degradation temperature $\left(T_{\max }\right)$ and the degradation temperature at various weigh loss rate $\left(T_{20}\right.$ and $\left.T_{30}\right)$ had a significant promoting effect. The results showed that antioxidants delayed the degradation of NR vulcanizates during thermal oxidation. Between $T_{5}$ and $T_{\max }$ the degradation temperature gradually increased. Compared with NR-0, $T_{5}$ and $T_{\max }$ of NR-1, NR-2, NR-3, and NR-4 increased by: $9^{\circ} \mathrm{C}\left(9^{\circ} \mathrm{C}\right.$ in $\left.T_{\text {max }}\right), 19^{\circ} \mathrm{C}$ $\left(15^{\circ} \mathrm{C}\right.$ in $\left.T_{\max }\right), 5^{\circ} \mathrm{C}\left(5^{\circ} \mathrm{C}\right.$ in $\left.T_{\max }\right), 13^{\circ} \mathrm{C}\left(29^{\circ} \mathrm{C}\right.$ in $\left.T_{\max }\right)$, respectively (Table 4). The degradation temperature $T_{20}$ and $T_{30}$ of NR-1, NR-2, NR-3, and NR-4 in comparison to NR-0 increased respectively by: $6^{\circ} \mathrm{C}$ and $5^{\circ} \mathrm{C}$ for $\mathrm{NR}-1,10^{\circ} \mathrm{C}$ and $9^{\circ} \mathrm{C}$ for NR-2, $1^{\circ} \mathrm{C}$ and $2^{\circ} \mathrm{C}$ for NR-3, $6^{\circ} \mathrm{C}$ and $7^{\circ} \mathrm{C}$ for NR-4. Compared with the degradation temperature of NR-0 under different weight loss, NR-1, NR-2 and NR-4 had the largest increase in degradation temperature at $T_{5}$, while NR-4 had the largest increase in degradation temperature at $T_{\max }$ (Table 4). For NR-1, NR-2 and NR-3 containing C1, $\mathrm{C} 2$ and BHT antioxidants, its degradation was relatively difficult in the initial stage and easier in the subsequent 


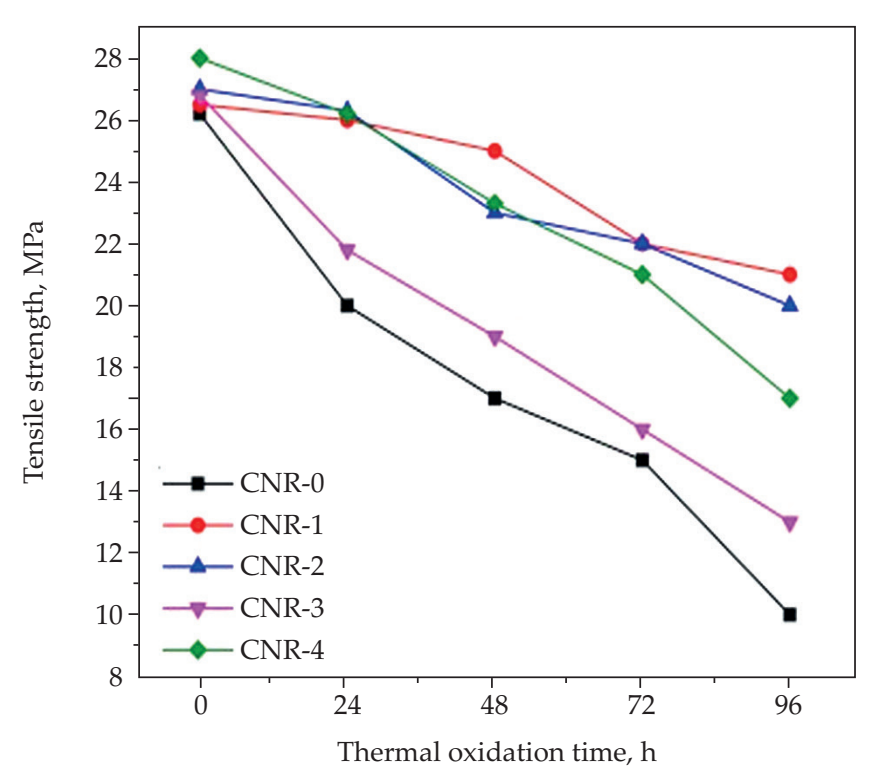

Fig. 10. Tensile strength of NR vulcanizates reinforced by carbon black with different antioxidants as a function of thermal oxidation time

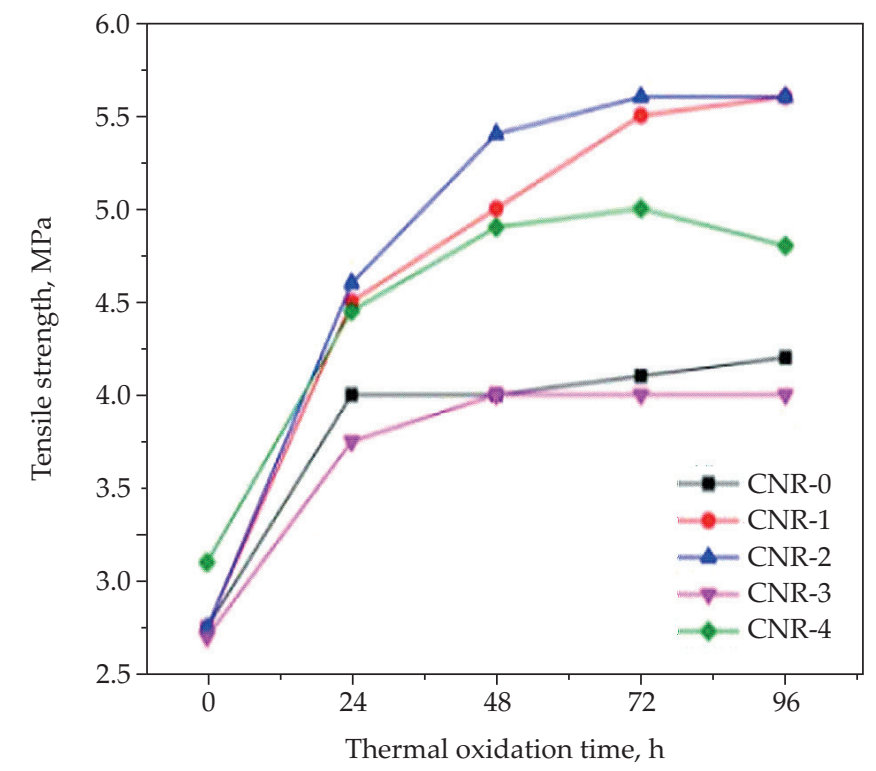

Fig. 12. Tensile strength at $100 \%$ elongation of carbon black reinforced NR vulcanizates with different antioxidants as a function of thermal oxidation time

stages. For NR-4 with 4010NA anti-aging agent, the degradation process was: hard to degrade in the initial stage, relatively easy to degrade in the middle stage, and hard to degrade in the latter stage. This difference might be due to different mechanisms of antioxidants action.

\section{Anti-aging mechanism of conjugated Schiff bases}

Conjugated Schiff bases are two-dimensional planar compounds with large $\pi$ bonds in the main chain. The main structure is connected by $\mathrm{C}=\mathrm{N}$ double bonds. The electron cloud of these compounds is evenly dis-

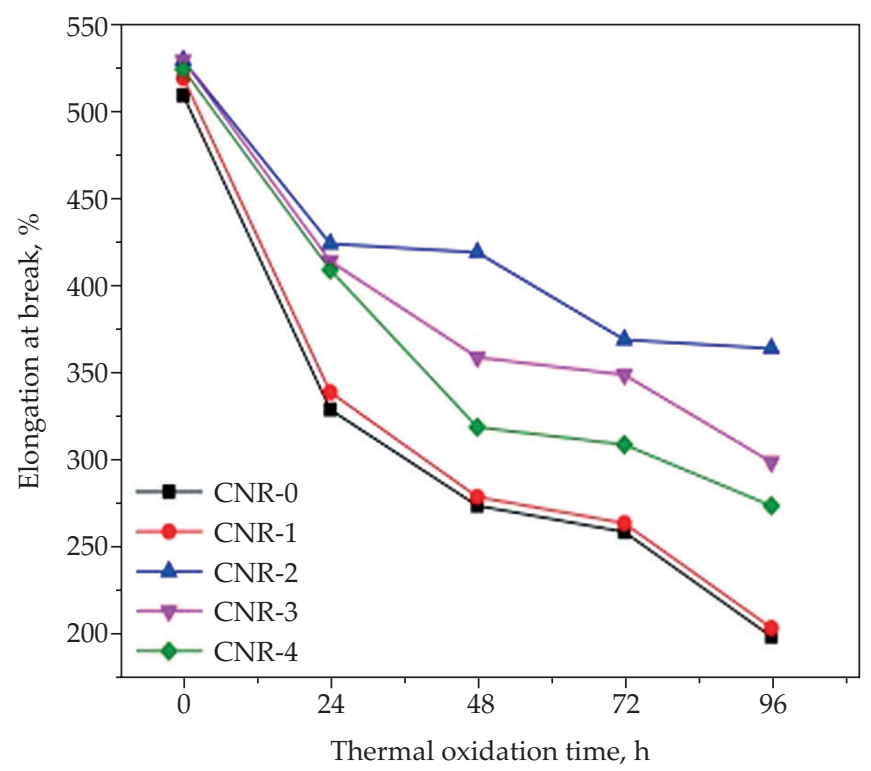

Fig. 11. Elongation at break of NR vulcanizates reinforced by carbon black with different antioxidants as a function of thermal oxidation time

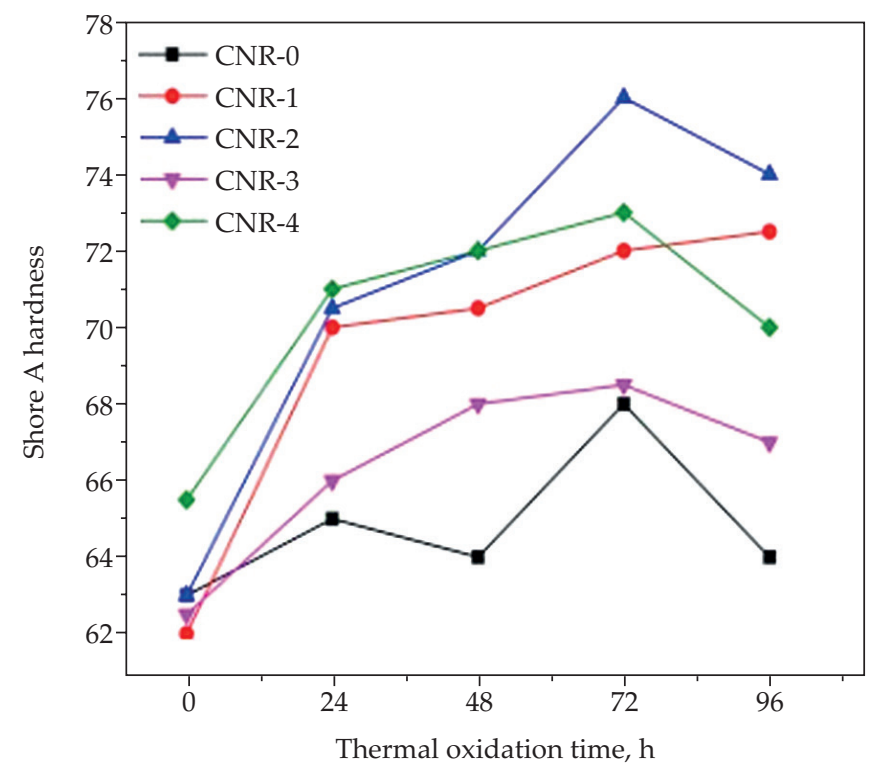

Fig. 13. Shore A hardness of NR vulcanizates reinforced by carbon black with different antioxidants as a function of thermal oxidation time

tributed and has a large degree of delocalization. Their structure could be modified by chemical or electrochemical methods to further expand the conjugated system of Schiff base compounds. When they are used as antioxidant, the electron cloud density of benzene ring is greatly improved. Due to the steric effect of benzene ring, it is conducive to the release of active $\mathrm{H}^{+}$, which can capture free radicals produced in the process of thermal oxidative aging. At the same time, the lone pair of electrons on nitrogen atom is also conducive to delaying or terminating free radical reaction, so that the conjugated Schiff base compounds have the effect of anti-aging. 


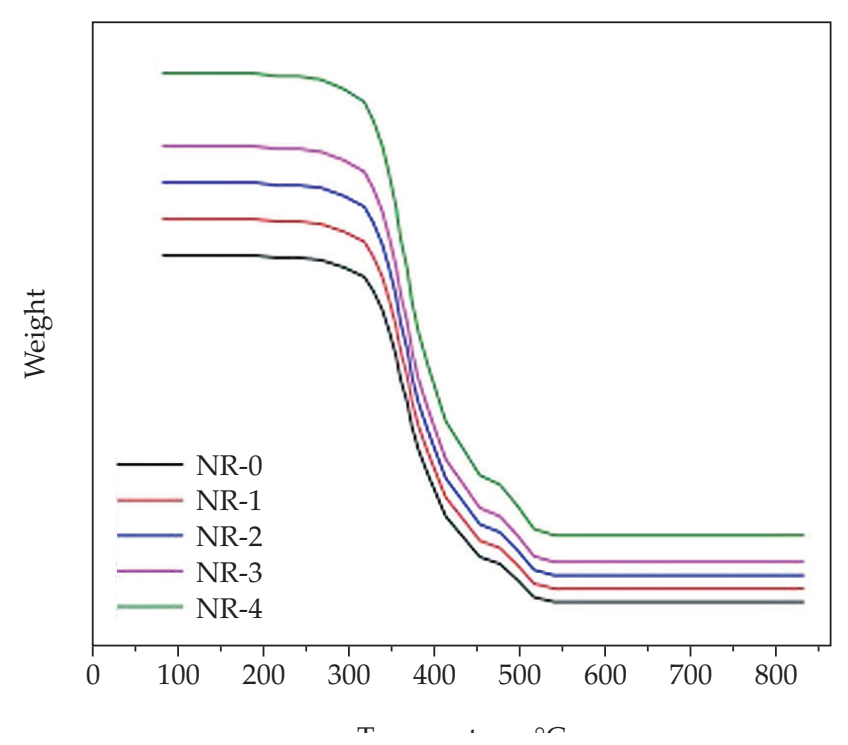

Fig. 14. Thermogravimetric curves of NR vulcanizates with different antioxidants

T a b l e 4. TGA data of NR vulcanizates

\begin{tabular}{l|l|l|l|l}
\hline Sample & $\begin{array}{c}T_{5} \\
{ }^{\circ} \mathrm{C}\end{array}$ & $\begin{array}{c}T_{20} \\
{ }^{\circ} \mathrm{C}\end{array}$ & $\begin{array}{c}T_{30} \\
{ }^{\circ} \mathrm{C}\end{array}$ & $\begin{array}{c}T_{\max } \\
{ }^{\circ} \mathrm{C}\end{array}$ \\
\hline NR-0 & 310 & 331 & 344 & 345 \\
NR-1 & 319 & 337 & 349 & 354 \\
NR-2 & 329 & 341 & 353 & 360 \\
NR-3 & 315 & 332 & 346 & 350 \\
NR-4 & 323 & 337 & 351 & 374 \\
\hline
\end{tabular}

As a new type of rubber antioxidant, conjugated Schiff base iron salt turned out to have a good effect on improving the anti-aging performance. Compared with other rubber antioxidants 4010NA and BHT, its performance has been significantly improved, but its production is slightly expensive. Conjugated Schiff base iron salt could be also a strong absorbing material to absorb and lose electromagnetic waves, so as to reduce the possibility of being detected. This rubber antioxidant could play an important role in avoiding being detected, therefore it could be applied to the high-precision purposes of the rubber in the future.

\section{CONCLUSION}

Improvement of the thermal aging resistance and applicability of natural rubber (NR) is presently a research hotspot. In this study, two new NR Schiff base antioxidants were synthesized from $p$-phenylenediamine and $p$-phenyleneformaldehyde or glyoxal in ethanol medium. The addition of Schiff alkali iron salt improved rheological and mechanical properties as well as thermal oxidation stability of NR vulcanizates. The thermal aging resistance of NR with added Schiff base antioxidant is related to its structure. Schiff base iron salt antioxidant may increase the electron density of benzene ring structure, which is conducive to the release of active hydrogen due to the steric effect of benzene ring. Active hydrogen can capture free radicals produced during thermal oxidative aging. The lone pair of electrons on the nitrogen atom is also helpful in delaying or terminating free radical reaction. After 96 hours of aging treatment, the oxidative tensile strength, 100\% elongation stress, and Shore A hardness of NR vulcanizates containing Schiff base iron salt were higher than those of industrial BHT and 4010NA, indicating that Schiff base iron salt has broad application perspectives as an effective antioxidant of NR.

\section{REFERENCES}

[1] Bonfils F., Huang H.Ch.: Rubber Reference 1999, $29,24$.

[2] Wang J., Zhang X.: Rubber Technology 2015, 3, 11.

[3] Wang J.: Application of conductive polymer materials in molecular printing techniques and antioxidants research, dissertation, Huazhong University of Science and Technology, 2007.

[4] Meng F.: Aging ison of amine inhibitor and organic monolsoil in ternary mixed adhesive (NR/BR/ SBR), dissertation, Shandong: Shandong University of Science and Technology, 2012. https://doi.org/10.7666/d.D302390

[5] Zhao X., Guo S., Chen J. et al.: Petrochemical Technology and Application 2010, 6, 530.

[6] Cataldo F.: Polymer Degradation and Stability 2001, 72, 287.

https://doi.org/10.1016/S0141-3910(01)00017-9

[7] Černá A., Cibulková Z., Šimon P. et al.: Polymer Degradation and Stability 2012, 97, 1724.

https://doi.org/10.1016/j.polymdegradstab.2012.06.012

[8] George R.S., Joseph R., George K.E.: International Journal of Polymeric Materials 1993, 23, 17. https://doi.org/10.1080/00914039308009655

[9] Wu J.: Journal of Beijing Union University (Natural Sciences) 2007, 02, 63.

[10] Su Ch.: Preparation and Antigenicity of NR Sulfide Rubber with High Extension, dissertation, Qingdao University of Science and Technology, 2009.

[11] Li G., Lv J., Sun H. et al.: Rubber and Plastic Technology and Equipment 2019, 4534.

Received 9 X 2021. 